\title{
Tomaž Erzar
}

\section{Trije povezovalni momenti v terapevtskem procesu odpuščanja in krščanski model odpuščanja ${ }^{1}$}

\section{Three Connecting Moments in the Therapeutic Process of Forgiveness and the Christian Model of Forgiveness}

Povそ̨etek: Številne raziskave ugotavljajo, da so neodpuščanje, zamera in jeza tesno povezani s slabim telesnim in psihičnim zdravjem. Psihični obrambni mehanizmi izolirajo bolečino od ostalega doživljanja, toda s tem razcepijo notranji svet človeka in mu onemogočijo, da bi se dotaknil bolečih plasti doživljanja, ki so pod jezo. Terapevtski model odpuščanja poskuša odpraviti vlogo jezne žrtve in vsebuje dva koraka: razgradnjo jeze oziroma zdravljenje krivice ter sočutje do storilca. Koraka sta med seboj povezana s tremi pogoji: spomin na lastno krivičnost, izkušnja odpuščanja ter spoznanje o viru dobrega. Te tri momente najdemo tudi v krščanski viziji odpuščanja, v kateri lahko odpušča samo nekdo, ki mu je bilo prej odpuščeno. Kristjan v molitvi Oče naš izraža svojo odprtost do vira, od katerega prejema sočutje in tolažbo, ter ju posreduje naprej.

Ključne besede: krivica, vloga žrtve, koraki odpuščanja, pravo sočutje, krščanstvo

Abstract: Numerous studies have found that unforgivingness, resentment and anger are closely linked to poor physical and mental health. Psychic defense mechanisms tend to isolate the pain from the rest of the experience, thus spliting the inner world of the victim and blocking the access to the painful layers of experience beneath anger. Attempting to eliminate the role of an angry victim, the therapeutic model of forgiveness involves two steps, the dissolution of anger or the healing of injustice, and compassion for the perpetrator. The steps are further connected with three moments: memory of one's own wrongdoing, the experience of being forgiven, and the recognition of the source of good. The same three moments are found in the Christian vision of forgiveness, in which only someone who was previously forgiven can forgive one's wrongdoers. In the prayer Our Father, Christians express their openness to the sour-

1 Prispevek je predelano slavnostno predavanje, ki ga je imel avtor na Tomaževi proslavi na Teološki fakulteti Univerze v Ljubljani dne 4. marca 2019. 
ce of good, from which they receive compassion and comfort before they offer them to others.

Key words: injustice, victim role, steps of forgiveness, true compassion, Christianity

"Neodpuščanje je kakor strup, ki ga spiješ sam in čakaš, da bo pokončal tvojega sovražnika. «²

Da neodpuščanje, jeza ali sovraštvo delujejo kakor strup, je bilo v zadnjih desetletjih podrobno raziskano in potrjeno: človek z jezo ali nepredelano krivico v sebi živi zelo slabo. Žrtve krivic so pogosteje kot drugi ljudje nagnjene k depresivnosti, fizičnim boleznim, odvisnostim in kroničnemu nezadovoljstvu (van Oyen Witvliet, Ludwig in Vander Laan 2001). Že več kot sto let se proučevanje človekovega blagostanja $v$ zahodnem svetu posveča posledicam vojnih travm, zlorabam šibkejših in odpravi njihovih negativnih posledic. Toda šele v zadnjem času spoznavamo, da na tej dolgi poti stojimo pred zadnjo, a skoraj nepremostljivo oviro: kako naj se žrtve znova veselijo življenja? In če je odpuščanje pravi zadnji korak, kako naj odpustijo in zaživijo v olajšanju? Kako naj se žrtve krivic otresejo jeze, zamere, zagrenjenosti, včasih tudi besa in sovraštva? In če gremo globlje, kako naj pomirijo bolečino, ki povzroča vsa ta čustva in spodbuja črne misli (Toussaint, Worthington in Williams 2015)?

\section{Jeza prikriva bolečino}

Prva oporna točka našega razmišljanja bo spoznanje, da jeza, sovraštvo in neodpuščanje, ki so kakor "strup«, ne nastanejo iz kake hudobije ali moralne šibkosti, ampak izhajajo iz bolečine in nemoči (Enright in Fitzgibbons 2015). So naravne posledice bolečine, osramočenosti, ponižanja ali frustracije. Za ponazoritev naj navedem neko prigodo. Profesor Robert Enright z Univerze v Wisconsinu že več kot 30 let raziskuje proces odpuščanja. Omenjam ga zato, ker je nekoč napisal raziskovalni načrt za zdravljenje krivic in spodbujanje odpuščanja pri zapornikih. Načrt je predvideval, da bi zapornike naučili prepoznati pretekle krivice, ki so jih spravile na pot kriminala, in jih po korakih pripeljali do točke, ko bi bili pripravljeni povzročiteljem krivic odpustiti. Načrt je bil sprva sprejet, nato pa so ga ocenjevalci nenadoma skoraj ogorčeno zavrnili, češ

»profesor Enright, vi ste popolnoma narobe razumeli terapijo odpuščanja, vaš načrt je narobe zastavljen. Zaporniki so tisti, ki morajo prositi družbo ali svoje žrtve za odpuščanje, ne pa da jih vi učite, kakor da so oni žrtve, ki naj odpustijo svojim družinam ali okolju, družbi, ki naj bi bili krivi za njihova dejanja."

Res je, če gledamo zgolj kriminalno vedenje in imamo pred očmi nepopravljivo tragične posledice tega vedenja, potem so seveda zaporniki za nas predvsem vir

2 Ta citat največkrat pripisujejo Nelsonu Mandeli. 
sovraštva in jeze. To sovraštvo jih žene v družbeno nesprejemljiva dejanja, za katera naj se naučijo sprejeti odgovornost, se pokesajo in prosijo za odpuščanje. Gre za razmišljanje, ki začenja pri posledicah (dejanjih) in se pomika nazaj proti viru (jezi, sovraštvu). In se tu ustavi. Pa vendar vsak, ki je bil deležen tradicionalne vzgoje, ve, da bi mu bilo dosti lažje, če bi kdo, namesto da graja njegova neprimerna oziroma jezna dejanja, razumel, kaj je za njimi, od kod izvirajo, iz kakšne stiske, prizadetosti, nemoči ali čustvenega nemira izhajajo (Simonič 2015, 491). In kako neizmerno blagodejno bi bilo, če bi kdo znal pomiriti in potolažiti naš nemir ali prizadetost.

Profesor Enright to grenko zgodbo zdaj pripoveduje z olajšanjem, saj se je njegov pristop izkazal za pravega. Številne njegove in druge raziskave so pokazale, da se človek lahko otrese jeze in sovraštva samo, če se kdo mimo ali preko posledic, ne glede na posledice, spusti do njegove bolečine in jo potolaži. Nekdo mora za jeznimi dejanji videti ranjeno srce in človeku pomagati, da se bo lahko spustil v svoje srce in prepoznal razdejanje, ki so ga tam pustile pretekle, največkrat nakopičene krivice in ponižanja.

Človeška psiha nas poskuša obvarovati pred bolečino. Okoli bolečine zato postavi pravi trdnjavski zid, ki ji preprečuje, da bi se širila in preplavila celotno duševnost. Prav ta zid preprečuje, da bi za jezo zlahka prepoznali bolečino (Stosny 2016). Kar koli človeka spominja na ta del njegove preteklosti in doživljanja, je zdaj odmaknjeno od zavesti in vsakdanjega življenja; zavest se kakor razdeli na običajno delovanje in odzivanje ter na del, ki ga skrbno varuje in se ga ogiba. Ogiba, čeprav se je povsem ovila okoli njega - in namesto da bi ta boleči del ostal na obrobju, postane njeno jedro. Človek postane ujetnik za zidom, ki naj bi ga varoval, zdaj pa ga zapira v ozek svet izogibanja, ogroženosti, previdnosti in osamljenosti.

Ena od žrtev spolnih zlorab v Cerkvi je na nedavnem srečanju v Rimu dejala: ${ }^{3}$

»Kdor je doživel zlorabo, bi rad vsemu naredil konec. A to ni mogoče. Želi pobegniti, zato se zgodi, da preneha biti on sam. Želi uiti in pobegniti samemu sebi. Sčasoma ostane popolnoma sam. Sam ostaneš, ker si se oddaljil in se ne moreš ali nočeš vrniti k samemu sebi. Kolikor pogosteje se to zgodi, toliko manj se vračaš k samemu sebi. Nekdo drug si, za vedno ostaneš nekdo drug. Nekaj nosiš v sebi, kot prikazen, ki je ostali ne morejo videti. Nikoli te ne bodo videli niti spoznali v celoti ... Poskusi, da bi se vrnil k svojemu resničnejšemu jazu in živel v prejšnjem svetu, kot pred zlorabo, so enako boleči kot sama zloraba. Vedno živiš v dveh svetovih hkrati.«

Tako je torej življenje človeka, zaprtega v dvojni, razklani svet njegove notranjosti: nikoli ni on sam, nikoli ni z drugimi tak, kot je v resnici, ker je del njega nedopovedljivo boleče ponižan in osramočen, in tega dela se izogiba (Centa 2015, 290). V to sobo človek ne hodi več. Počasi postane poleg sebe samega še nekdo drug, nekdo, ki pazi na bolečino, ki jo nosi v sebi.

3 Družina, 3. 3. 2019, 5. 


\section{Na razpotju: vloga žrtve ali pot odpuščanja}

Ena od rešitev, ki jo ima pred seboj zaradi bolečine razklana ali z zlorabo dobesedno okužena in zastrupljena oseba, je počasno dolgotrajno okrevanje. Problem nastane, ker to okrevanje žrtev sicer krepi, toda kot žrtev. Namesto zdravja in polnega življenja se njeno okrevanje lahko izteče v stanje, ki mu pravimo vloga žrtve. Vloga žrtve pomeni trajno zasidranost v vlogo nemočne, napol jezne, napol zagrenjene žrtve, ki se niti ne zaveda, kdaj bi s svojim jeznim ali celo sovražnim vedenjem lahko postala storilec (Maros 2015, 59). Bivša žrtev, ki ne more do svoje bolečine, postopoma postaja storilec (Freyd 2002). Občasno izbruhne, in se nato povsem utiša, do naslednjega izbruha. Ali kakor pravi izrek: „Vsi smo žrtve bivših žrtev.«

Na enem od mozaikov p. Marka Rupnika v Narodnem svetišču papeža Janeza Pavla II v Washingtonu je prizor iz svetopisemske zgodbe o izgubljenem sinu. $\mathrm{Na}$ levi strani mozaika je obraz starejšega brata, ki jezno gleda na mlajšega brata, ki si je, tako on misli, nezasluženo pridobil nazaj očetovo naklonjenost. Njegov obraz je prežet z bolečino in nejevoljo, je obraz razdeljenega človeka, lahko bi rekli človeka, ki doživlja, da se mu godi krivica in je ujet v vlogi žrtve. Pogled nejevoljno usmerja na brata, ki kljub temu, da je v življenju vse naredil narobe, mirno živi življenje kot celoto, z vsemi napakami vred. Bratovo življenje je v celoti sprejeto v naročje Očeta. Na eni strani mozaika torej vidimo obraz zagrenjenega brata, ki lahko kmalu postane Kajnov obraz, se pravi, obraz storilca, ki ubije lastnega brata. Na drugi je obraz brata, ki živi polno življenje in je v celoti lahko on sam, ker je v celoti sprejet tak, kot je. Lahko bi dodali, človek živi v celoti, kadar se v celoti preda drugi osebi (Žalec 2015, 224-225).

Še eno globoko misel lahko preberemo na mozaiku p. Marka Rupnika. Kdaj bivša žrtev, ki ne more do svoje bolečine, postane storilec? Koga prizadene tak človek, komu naredi krivico in povzroči bolečino? Zagrenjena žrtev, zdaj že skoraj storilec, tudi dejansko postane storilec, kadar sreča drugega, ki živi celoto, ker ga življenje $v$ celosti spominja na njegovo bolečino, na katero se ne želi spominjati. ${ }^{4}$ To je žalostna in težka pot Kajna ter pot starejšega brata v zgodbi o izgubljenem sinu.

Prva pot iz vloge žrtve je torej pot, kjer žrtev bolj ali manj nehote postane storilec. Druga pot, ki jo ima pred seboj razklana oseba, je proces odpuščanja. Ta proces bo nujno vključeval podiranje zidu, soočenje z bolečino in odpiranje zaprtega sveta. Odpuščanje zato ni pozaba krivice niti samo iskanje pravice. Tudi ni popuščanje storilcem, ker ga žrtev naredi zaradi sebe, zaradi svoje razklanosti. In zato tudi ni moralna vzvišenost žrtve nad storilcem. Odpuščanje ni sprava, lahko pa vodi do sprave, če seveda tudi storilec naredi prave korake. Ko govorimo o procesu odpuščanja, gre za terapevtski model, ki vključuje samó žrtev in je v tem pogledu enostranski. Tako definirano odpuščanje vključuje dva večja koraka:

- iskanje varnosti, prizadevanje za pravico in zdravljenje krivice; ta korak bo končan, ko se bo žrtev počutila dovolj varno, da bo začela podirati obrambni zid:

4 Prim. Rupnikov komentar zgodbe o egiptovskem Jožefu v »Brate iščem « (2000, 58-59). 
odpirati se svetu, živeti v enem kosu; ko se bo lahko zatekla v naročje svojih najbližjih;

- drugi korak je sočutje do povzročitelja; ta korak je možen šele, ko se žrtev storilca ne boji več, ko ni več v vlogi žrtve, ampak se lahko kot nekdo, ki živi celoto, približa nekomu, ki živi razklano, dvojno, nejevoljno, sovražno življenje.

Če odpuščanje definiramo na ta način, opazimo, da gresta lahko koraka vsak v svojo smer. Prvi lahko teži v smer, kjer se kdo ukvarja samo s sabo in ostane v vlogi žrtve, drugi pa lahko vodi k nekakšnemu moralizmu, kjer se kdo sicer plemenito posveča drugim, celo svojemu storilcu, toda pri tem najverjetneje sam ni ozdravljen, ker se ne ukvarja s sabo in svojo bolečino. Njegovo odpuščanje je v tem primeru prehitro, opravljeno iz dolžnosti in nepristno (Baumeister, Exline in Sommer 1998, 86).

Obstaja torej nevarnost, da proces odpuščanja razpade na dva dela, in s tem seveda izgine, se razpusti v dva pola, ki vsak zase ne vodita nikamor. Prvi pol vodi nazaj, v nevarnost, da kdo nikoli ne zapusti vloge žrtve in se nikoli ne odpre možnosti, da je svet okoli njega prijazen in dober in da so ljudje vredni zaupanja (Kompan Erzar in Simonič 2010). Drugi pol vodi v nevarnost, da se odpuščanje razume kot verska zapoved ali moralna naloga, ki se ji srce upira - in tako v skrajnem primeru izsili iz sebe nekakšne bolj ali manj neiskrene izraze sočutja. Odpuščanje takrat postane prazno. Žrtve se razumljivo takemu vsiljenemu odpuščanju upirajo: kako naj žrtev v grozi in strahu pred novimi zlorabami odpusti storilcu in od kod naj jemlje moč in sočutje v času, ko sama najbolj potrebuje oporo, razumevanje in sočutje do sebe!

\section{Trije pogoji odpuščanja}

Ko se torej odločimo za pot odpuščanja v nekem terapevtskem procesu, sploh ni jasno, ali se bo ta pot iztekla dobro, sploh ni rečeno, da ta pot ima zaključek. Zato je ključno, da imamo na tej poti vodnika ali model, kako naj odpuščanje izpeljemo (Worthington idr. 2006, 33). Model ljudi, ob katerih čutimo, da so svojim preganjalcem resnično odpustili. Zdaj si oglejmo, do kakšnih spoznanj je prišlo proučevanje terapevtskega procesa odpuščanja.

1. Ljudje se strinjajo, da k odpuščanju prispeva spomin na to, da so bili nekoč, ko niso zmogli nositi svoje bolečine, tudi sami storilci in da so takrat potrebovali sočutje in odpuščanje (Enright 2001). Ta spomin naravno poveže žrtev in vse storilce tega sveta; zdaj se lahko žrtev povsem vživi v kožo neštetih storilcev. Vsi, vključno z mano, povzročamo krivice iz lastne bolečine, ki je ne moremo več nositi sami. Toda, pozor, spomin na lastno krivičnost ne pomeni izenačenja vseh krivic, češ, saj vsi včasih koga ranimo, torej je tudi zloraba pač samo malo večja krivica.

2. Drugi moment, ki prispeva k odpuščanju, je lastna izkušnja ali spomin, da mi je bilo takrat, ko sem storil komu krivico, odpuščeno, kar pomeni, da je nekdo razumel, iz kakšne stiske se je porodila. Gre za izkušnjo, ko smo bili v krivičnem 
stanju jeze ali škodoželjnosti ali pa celo sovraštva sprejeti in potolaženi (Wade in Worthington 2005). Ko smo storilci, potrebujemo sočutje in razumevanje bolj kot takrat, ko smo žrtve. Ko smo žrtve, nam sočutje tako rekoč pripada, ker trpimo in smo nemočne žrtve. Saj zato je vloge žrtve tako privlačna. Ko pa smo storilci, nam ne pripada nič - samo kazen, pregon, izgon. Spomin na lastno krivičnost se tako dopolni s spominom na nezasluženo razumevanje in sočutje.

3. Tretji moment je spoznanje, ki izhaja iz prvih dveh momentov, in sicer, da obstaja sočutje, ki ima vir drugod in deluje samostojno in neodvisno od mene. Ko sem bil storilec, sem potreboval in dobil sočutje, čeprav si ga nisem zaslužil. Prav zato ima to nezasluženo sočutje povsem drugo težo. Je pravo sočutje, ker je neodvisno od mene in mojega prizadevanja, ker je prišlo do mene kljub vsem oviram, ki sem jih sam postavil s svojimi dejanji. Na to sočutje se lahko zanesem, ker je močnejše od moje krivde in krivičnosti. Vidi v moje ranjeno srce in mojo razklanost, ki se je otepam tako, da sem sovražen in povzročam krivice (Worthington idr. 2006, 39).

Če povzamemo: ko se žrtev spusti v svoje srce, tam ne bo našla samo bolečine, ki so ji jo povzročili drugi, ampak tudi bolečino, ki jo je preložila na druge. In če zmore ostati ob tej bolečini, ob tem temnem delu svojega srca, bo našla hkrati z njo tudi nezasluženo sočutje do te bolečine. Takrat oseba ni več žrtev, ni več v vlogi žrtve, in hkrati se ne boji več svojega storilca, ker pozna vse storilce tega sveta od znotraj; ve, kaj se skriva pod jezo in sovraštvom, ve, od kod izhajajo krivična dejanja: iz nepriznane ali neprepoznane bolečine in razklanosti, ki jo pozna tudi sama in za katero ve, da jo pravo sočutje premaga in zaceli. Takrat modeli oživijo, saj lastna izkušnja, da mi je bilo odpuščeno, deluje kot model, kako naj odpustim. Modeli postanejo ne samo naši vodniki, ampak sopotniki. In odpuščanje takrat postane realna možnost, postane globoko olajšanje, pot vrnitve v svet dobrega in dobrih ljudi (Petkovšek 2018, 44-50).

Te tri vezne elemente, ki jih je izpostavilo proučevanje procesa odpuščanja, najdemo v samem jedru krščanskega odpuščanja, ki pravi, da lahko odpusti samo nekdo, ki se zaveda, da mu je bilo odpuščeno (Osredkar 2018, 321). Odpuščeno mu ni bilo kar koli, ampak neodpustljivo. Nekaj, česar nihče izmed nas pri sebi ne more sprejeti. Poskusimo molitev Oče naš (upajmo, da ne preveč na silo in preveč okrnjeno) prevesti v jezik čustvovanja in doživljanja.

Odpusti nam naše dolge - sem storilec in se spominjam svojih napak, prosim za sočutje, za ponovno celoto sebe in svojih odnosov, nisem samo žrtev, prosim za tolažbo dela svojega srca.

Kakor tudi mi odpuščamo svojim dolžnikom - ko se spominjam, kako sem se počutil kot storilec in da mi je bilo odpuščeno, lahko odpuščam, ker poznam storilčevo bolečino.

Kakor mi je odpuščeno, tako odpuščam. Vsi trije elementi - model, spomin in izkušnja - so tu združeni v enem. Človek v tej molitvi izraža svojo odprtost do vira; iz istega vira prejemam sočutje in dobro in ga posredujem naprej. 


\section{Sklep}

V procesu človeškega odpuščanja, kakor se to vedno znova pojavlja v različnih oblikah in družbah, se človek odpira sočutju ali dobremu, ki ga presega in je od njega neodvisno. Človek se odpira srečanju, ki ga ni mogoče izsiliti, ki je onstran "prav« in »narobe«, je od posamezne osebe neodvisni vir odpuščanja tako sebi kot drugim. S tem odpiranjem srca človek postane sodelavec tega vira dobrega in je spet celota. Odpuščanje je način, kako človek prisluhne lastnemu srcu in za hip spozna skrivnostno naravo ali pot dobrega v svojem srcu in v srcu soljudi. Od tod veje neko olajšanje srca, zdravilni vzdih olajšanja. Kdor hodi po poti odpuščanja, odpuščanja sebi in drugim, bo imel možnost, da izkusi dobro na povsem enkraten način, kot dobro, ki se mu približa samo od sebe.

Kaj je odpuščanje v krščanski perspektivi? Krščansko odpuščanje za razliko od terapevtskega modela poteka na dveh ravneh - na ravni telesne bolečine ali čustvene okrnjenosti in travmiranosti (slepota, hromost, gobavost, neplodnost, samskost) in na ravni neljubljenosti. Med obema je pomembna razlika, kolikor je neljubljenost ime za tisto črnino človeškega srca, ki se je človek zave, ko rani ljubljeno osebo. Vrnimo se k prizoru obeh bratov, ki ga lahko razumemo kot potovanje človeka skozi čas ali kot brezčasno stvarnost v človekovem srcu.

Starejši brat je na točki, kjer je bil mlajši brat v času, ko je odhajal od doma. Jezen je in zagrenjen. In - ključni moment - oče bo šel tudi za starejšim bratom, kakor je stekel nasproti mlajšemu sinu, objel bo oba. To je izvirna krščanska obljuba in vizija ali model odpuščanja. Lahko pa prizor razumemo kot razgrnitev človekovega srca, kadar je to razdeljeno: v enem delu srca je neodpuščanje, v drugem tolažba in spomin. Življenje v jezi, brez doma, je boleče, zagrenjeno. Življenje v sovraštvu in zavisti je zastrupljeno življenje. $V$ drugem delu srca je spomin, ki se ga človek noče spominjati in ga zato preganja, da bi pomiril sebe in da bi še naprej lahko živel v dvojnosti srca. Kar torej človek preganja v svojem bratu, je del njega samega, obzidani del, ki se ga ne more dotakniti. Če bi se ga dotaknil, bi spoznal, da ni črn, da je bil črn samo zanj, da pa je pri Očetu tudi ta del že ves čas potolažen in sprejet. Oče pravi: Ti si bil ves čas pri meni, svet sem ustvaril zate in brez tebe ni popoln.

\section{Reference}

Baumeister, Roy F., Julie J. Exline in Kristin L. Sommer. 1998. The victim role, grudge theory, and two dimensions of forgiveness. V: Everett L. Worthington, ur. Dimensions of Forgiveness, 79-104. Philadelphia: Templeton.

Centa, Mateja. 2015. Stigmatizacija čustvenosti in strah pred sočutjem onemogoča proces sprave. Bogoslovni vestnik 75, št. 2:287-296.

Enright, Robert D., in Richard Fitzgibbons. 2015. Forgiveness Therapy. Washington: American Psychological Association.
Freyd, Jennifer. 2002. In the wake of terrorist attack hatred may mask fear. Analyses of Social Issues and Public Policy 2:5-8. https://doi.org/10.1111/j.15302415.2002.00020.x

Kompan Erzar, Katarina, in Barbara Simonič. 2010. Marital infidelity: Relational family therapy perspective on adult detachment. Journal of Family Psychotherapy 21, št. 2:105116. https://doi.org/10.1080/08975353.2010.4 83630 
Maros, Zorica. 2015. Od maščevalnosti vojne do maščevanja: (ne)možnost odpuščanja. Bogoslovni vestnik 75, št. 1:51-64.

Osredkar, Mari Jože. 2018. Forgiveness as the Summation of the Gospel Ethics of God. Bogoslovni vestnik 78, št. 2:313-323.

Petkovšek, Robert. 2018. Svoboda med žrtvovanjem in darovanjem. Bogoslovni vestnik 78, št. 1:33-51.

Rupnik, Marko. 2000. »Brate iščem«: Lectio divina o egiptovskem Jožefu. Koper: Ognjišče.

Simonič, Barbara. 2015. Ranljivost sodobnih družin in spodbuda k materinski rahločutnosti v pastoralni skrbi za družine. Bogoslovni vestnik 75, št. 3:487-494.

Stosny, Steven. 2016. Compassion Power: Helping Families Reach Their Core Value. The Family Journal 12, št. 1:58-63. https://doi. org/10.1177/1066480703259041

Toussaint, Loren, Everett Worthington in David R. Williams, ur. 2015. Forgiveness and Health: Scientific Evidence and Theories Relating Forgiveness to Better Health. Dordrecht: Springer. https://doi.org/10.1007/978-94-017-9993-5 van Oyen Witvliet, Charlotte, Thomas E. Ludwig in Kelly L. Vander Laan. 2001. Granting forgiveness or harboring grudges: Implications for emotion, physiology, and health. Psychological Science 12:117-123. https://doi. org/10.1111/1467-9280.00320

Wade, Nathaniel G. in Everett L. Worthington. 2005. In Search of a Common Core: A Content Analysis of Interventions to Promote Forgiveness. Psychotherapy: Theory, Research, Practice, Training 42, št. 2:160-177. https://doi. org/10.1037/0033-3204.42.2.160

Worthington, Everett L. in Steven J. Sandage. 2015. Forgiveness and Spirituality in Psychotherapy: A Relational Approach. Washington: American Psychological Association.

Žalec, Bojan. 2015. Človekovo nesprejemanje temeljne resnice o sebi kot izvor njegovih psihopatologij, nasilja in nesočutnosti. Bogoslovni vestnik 75, št. 2:221-232. 